\title{
Green production of a novel sorbent from kaolin for capturing gaseous $\mathrm{PbCl}_{2}$ in a furnace
}

Jianrui Zha ${ }^{\mathrm{a}, \mathrm{b}}$, Yaji Huang*,a ${ }^{*}$, Peter T. Clough ${ }^{\mathrm{b}}$, Zhipeng Xia ${ }^{\mathrm{a}}$, Zhicheng Zhu ${ }^{\mathrm{a}}$, Conghui Fan ${ }^{\mathrm{a}}$, Mengzhu Yu

${ }^{\mathrm{a}}$, Yongliang Yan $^{\mathrm{b}}$, Haoqiang Cheng ${ }^{\mathrm{a}}$

${ }^{a}$ Key Laboratory of Energy Thermal Conversion and Control of Ministry of Education, School of Energy and Environment, Southeast University, Nanjing 210096, China

${ }^{\mathrm{b}}$ Energy and Power Theme, Cranfield University, Bedford MK43 0AL, United Kingdom

Corresponding Author:

*Y. Huang. Email: heyyj @ seu.edu.cn; Fax: +86 02583792811.

\begin{abstract}
The pollution of semi-volatile heavy metals is one of the key environmental risks for municipal solid waste incineration, and in-situ adsorption of metals within the furnace by mineral sorbents such as kaolin has been demonstrated as a promising emission control method. To lessen the consumption of sorbent, a novel material of amorphous silicate was produced from kaolin through pressurised hydrothermal treatment. Its performance of gaseous $\mathrm{PbCl}_{2}$ capture was tested in a fixed bed furnace and compared with unmodified kaolin and metakaolin. With increasing temperature, the adsorption rates for all sorbents declined due to higher saturated vapour pressure, while the partitions of residual form lead increased which indicated higher stability of heavy metals in the sorbent because of melting effect. The new sorbent with a larger surface area and reformed structure presented $26 \%$ more adsorption efficiency than raw kaolin at $900{ }^{\circ} \mathrm{C}$, and increasing the modification pressure improved these properties. Additionally, the production of this high-temperature sorbent was relatively inexpensive, required little thermal energy and no chemicals to produce and no waste effluent was generated, thus being much cleaner than other modification methods.
\end{abstract}

KEYWORDS: Kaolin; Adsorption; $\mathrm{PbCl}_{2}$; High temperature; Hydrothermal modification. 


\section{Introduction}

Incineration of municipal solid waste has been widely used as an effective treatment for volume reduction and energy recovery, but there is a risk of heavy metal emissions to the atmosphere, which can be harmful human health. This problem is much more serious particularly in developing countries where there is often lack of waste classification and hazardous waste such as electronic waste with a high content of heavy metals is burning with general municipal waste. Some of these heavy metals, such as lead, cadmium and zinc, have a semi-volatile behaviour within an incineration furnace, which means these elements can be vaporised due to the high temperatures of combustion but then return a solid phase at a relatively lower temperature. These heavy metals can easily become enriched in submicron particles through the mechanism of vaporization-condensation and escape from dust collection systems (Wang et al., 2016; Gale et al., 2003). Since it is very difficult and expensive to increase the removal efficiency of ultrafine $(\leq 1 \mu \mathrm{m})$ particles, it is necessary to consider alternatively capturing those vaporised elements in-situ of the furnace by the addition of a cheap mineral before the heavy metals are condensed into fine particles that can be elutriated from the process (Wang et al., 2019; Xu et al., 2018).

Because of its well-known high performance and the fact it is produced at scale, kaolin is often chosen as a sorbent for in-furnace capture of semi-volatile metals at high temperatures, and can also further control alkali metal induced slagging, submicron particulate matter formation and heavy metal emission (Xing et al., 2019; Wang et al., 2018). Kaolin is a 1:1 layered aluminosilicate clay with a formula of $\mathrm{Al}_{2} \mathrm{Si}_{2} \mathrm{O}_{5}(\mathrm{OH})_{4}$, where every adjacent layer is connected by hydrogen bonds. The layered structure makes kaolin easily stripped into slices with high 
surface area, leading to wide utilisation in catalysis, sorbents and as a filler material ( $\mathrm{Pt}^{2}$ cek et al., 2013). When heated, kaolin is converted to metakaolin by dehydration (eliminating adsorbed or bound water) and dehydroxylation, which then forms an amorphous phase and finally after more severe heating would form quartz and mullite (Gasparini et al., 2013).

The reaction mechanism between kaolin and metals at high temperature is that the dehydroxylation of kaolin reduces the coordination of atomic $\mathrm{Al}$ from six to five or four to expose reactive sites for adsorption (Zhang et al., 2018; Wang et al., 2015). As for the factor of temperature, many studies concluded there is an optimal temperature for the adsorption reaction, while at lower temperature the eutectic melting point declines, at higher temperatures the structure can collapse resulting at lost surface area (Zhang et al., 2019; White et al., 2010). The presence of moisture or hydroxylation, which can be regarded as a mineralizer, helps kaolin eutectic melting so that the adsorbed metal can be diffused into the liquid phase and the surface remains active (Yu et al., 2020; Temuujin et al., 1999; Linak et al., 1993). Metakaolin can also adsorb gaseous metal chlorides without the presence of moisture, but its adsorption ability is reduced without water vapour being present (Yu et al., 2020; Wang et al., 2018). To enhance the capture efficiency of semi-volatile metals at high temperatures and reduce the sorbent consumption several modification methods on aluminosilicate minerals have been reported, where the general principles were to expose active sites and enlarge the surface area. Acid treatment $\left(\mathrm{HCl}, \mathrm{H}_{2} \mathrm{SO}_{4}\right.$, etc.) and base treatment (such as $\left.\mathrm{NaOH}\right)$ are common methods to remove part of aluminum and silicon respectively, in order to selectively alter the local structure of the aluminosilicate minerals to enhance the surface area and to create more active sites (Zhang et al., 2017; Sun et al., 2018; Hartanto et al., 2019). For example, attapulgite was 
modified by acid-treated and added into the fuel to reduce the emission of particulate matter and heavy metal during combustion (Xu et al., 2019). Intercalation-exfoliation is another modification method, where small molecules like urea and potassium acetate can be diffused into the interlayer structure and break the hydrogen bonds so that more reaction sites from 4 or 5-coordinate aluminium atoms can be exposed at high temperature, which enhanced the sorbent's adsorption ability of semi-volatile metals including sodium, potassium and lead at high temperature (Xing et al., 2019; Zhang et al., 2017; Lai et al., 2019; Zhang et al., 2019). Hydrothermal treatment is widely used for the synthesis of zeolite from aluminosilicate including kaolin, and the product generated can be altered by varying the operating parameters and additives used in the production (Krol et al., 2018; Wu et al., 2013). Pressurised hydrothermal treatment can generate different minerals and accelerate the synthesis process (Zhang et al., 2011; Hayashi et al., 2010), and has proved to create larger surface area silicates (Sun et al., 2008). However, only a two studies in the literature have reported modifying kaolin by hydrothermal methods and most focused on the dihydrogen during the hydrothermal treatment, but neither studied its aluminosilicate structure nor have been further used as a high temperature sorbent (Zemenová et al., 2014; Kloužková et al., 2013). Moreover, production of functionalised kaolin for heavy metal in-furnace capture usually requires expensive chemicals that not only consume extra resources and may produce a waste effluent requiring clean up, but can also lead to corrosion of reaction vessels and pipework. Thus, the hydrothermal treatment of kaolin without other chemicals excels in these areas but its performance needs investigating, as does the mechanism of the enhancement effect.

In this paper, an amorphous silicates material was newly developed derived from metakaolin 
by pressurised hydrothermal treatment. Its capture performances of gaseous $\mathrm{PbCl}_{2}$ was tested in a fixed bed tube furnace at high temperature and its adsorption efficiency was compared with raw kaolin and metakaolin. In order to further reveal the adsorption mechanism, the chemical and physical properties of sorbents were analysed and the species of captured heavy metals were determined by two leaching steps. As only a little more thermal energy was utilised instead of adding additional chemicals, this study contributes to controlling heavy metals by developing a cheaper and greener production method for modified kaolin.

\section{Materials and methods}

2.1 The kaolin and its hydrothermal modification

The dominant chemical compositions of the raw kaolin are $\mathrm{SiO}_{2}(42.8 \%), \mathrm{Al}_{2} \mathrm{O}_{3}(40.8 \%)$ and $\mathrm{H}_{2} \mathrm{O}(14.2 \%)$, and Table $\mathrm{S} 1$ has further details of this chemical composition of the kaolin. To obtain the hydrothermally modified product, firstly the raw kaolin (RK) was heated at $800{ }^{\circ} \mathrm{C}$ for 2 hours to get metakaolin (MK). Then the MK was blended with deionized water at a mass ratio of 1:3 (MK:water), this mixture was then stirred and heated in a pressurised reaction kettle for hydrothermal treatment at $180{ }^{\circ} \mathrm{C}$ for 2 hours, of which the operating pressures were 0.9 , 2.8 and 4.0 MPa (named as $\mathrm{HA}, \mathrm{HB}$ and $\mathrm{HC}$ respectively). Finally, after drying at $50{ }^{\circ} \mathrm{C}$ until the mass was constant, the product was compressed into a tablet, broken and sieved into particles between $0.2-0.3 \mathrm{~mm}$ to reduce the effect of heat transfer factor.

2.2 The vaporization and adsorption of heavy metal chlorides

The adsorption tests were conducted on a two-stage fixed bed reactor, where the tube furnace was made up of quartz with the height of $750 \mathrm{~mm}$ and inner diameter of $40 \mathrm{~mm}$. The 
temperatures of two heating zones were controlled independently by a heating control box. Heavy metals were vaporized in the upper zone and adsorbed by minerals at the lower zone. The flue gas leaving the reactor was absorbed by passing them through a nitric acid solution. More details of the reactor set up can be found in our previous work (Yu et al., 2020).

The procedure for the tests are as follows. A ZrO crucible suspended in the upper zone was filled with $0.05 \mathrm{~g}$ of $\mathrm{PbCl}_{2}$, which was then heated and the produced heavy metal vapour was carried by $\mathrm{N}_{2}$ flow to the lower zone of the reactor $(130 \mathrm{~mL} / \mathrm{min})$. This gas stream passed over the sorbent that was supported upon the sand bed.

Since the vapour point of $\mathrm{PbCl}_{2}$ is lower than $600{ }^{\circ} \mathrm{C}$ (Wang et al., 2019), the temperature of the upper zone was set as $800{ }^{\circ} \mathrm{C}$ to ensure it was thoroughly vaporized. The reaction temperatures in the lower zone were $600,700,800$ and $900{ }^{\circ} \mathrm{C}$. To guarantee the temperature of the sorbent had reached to the set temperature before the adsorption reaction started, the lower zone was heated before the upper zone. The detailing temperature control procedures are available in Table S2. It should be noted that in our previous work (Yu et al., 2020), the sorbent and sorbate were heated simultaneously so that the sorbent might adsorb gaseous heavy metal below the set point during the rising temperature, which could lead to different results.

\subsection{Calculation of heavy metal distributions}

To evaluate the retention effect and the adsorbed formations of heavy metals, the sorbents after adsorbing were analysed by two methods. The first method involved leaching the product sorbent in aqua regia under vigorous stirring at $25^{\circ} \mathrm{C}$ for 2 hours to extract leached form of the heavy metals. Any material that did not dissolve in the acid solution was defined as the residual form (Zha et al., 2018). The second method involved digesting the product sorbent thoroughly 
with $\mathrm{HCl}-\mathrm{HNO}_{3}-\mathrm{HF}$ to obtain the total amount of adsorbed heavy metals. Through leaching, the lead deposited on the sorbent surface, and that which combined with aluminium oxides, was separated into the solution and the rest diffused inside the silicate lattice remained. The concentrations of lead in those two solutions were measured by an atomic absorption spectrometry, and the distributions of lead were calculated as follow equations:

$$
\begin{aligned}
& X_{t}=\frac{M_{t}}{M_{0}} \\
& P_{a}=\frac{M_{a}}{M_{t}}=1-P_{b}
\end{aligned}
$$

Where, $M_{a}, M_{t}$ and $M_{0}$ are masses of the element in leaching, total digestion solution and the total mass of element input (calculated by the $0.05 \mathrm{~g} \mathrm{PbCl}_{2}$ ), and $X_{t}, P_{a}$ and $P_{b}$ are the adsorption efficiency, the partitions of leached and residual form in the adsorption product respectively. Three parallel tests were conducted for each condition.

\subsection{Sample analysis}

The chemical and physical structure properties of sorbents were analysed by Fourier transform infrared spectrometry (FTIR), thermo-gravimetric analysis (TGA), X-ray diffraction (XRD) and Brunauer-Emmett-Teller method (BET) analysis. Magic angle spinning nuclear magnetic resonance (MAS-NMR) was used to study the coordination of $\mathrm{Al}$ and $\mathrm{Si}$ atoms for the sorbents before and after adsorption. The morphology was analysed by scanning electron microscopy (SEM) and Transmission Electron Microscopy (TEM).

\section{Results and discussion}

\subsection{The properties of sorbents}

According to the composition analysis, sorbents would release moisture when heated. TGA 
results are shown in Figure 1 to measure the quantities and bind strength of water content (or hydroxyl) in the structure of the sorbents. The final weight loss fractions were $14.2 \%$ for kaolin, and metakaolin had been already dehydrated after calcination with slightly weight loss of $0.3 \%$, while the modified kaolin gained water or hydroxyl from hydrothermal treatment with the increasing pressure and thus presented weight losses of $3.9 \%$ for HA, $5.1 \%$ for $\mathrm{HB}$ and $8.8 \%$ for $\mathrm{HC}$, respectively.

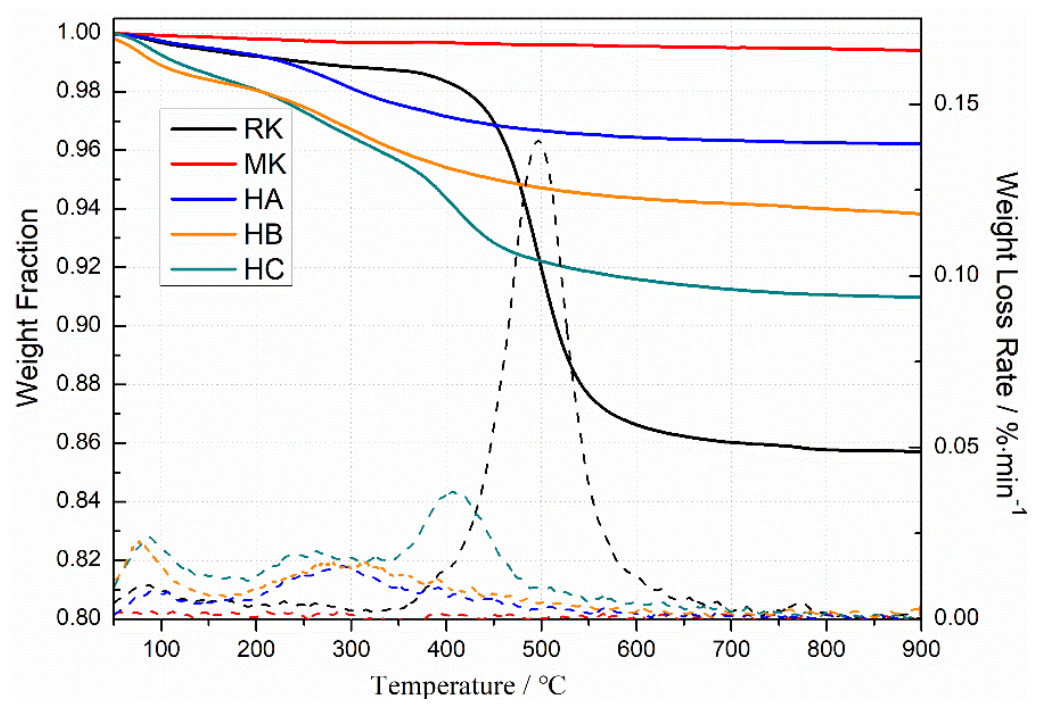

Figure 1. TGA (solid lines) and DTG (dash lines) curves of five sorbents. Heating rate

$10{ }^{\circ} \mathrm{C} / \mathrm{min}$.

DTG (differential thermo-gravimetric) analysis was also calculated and shown in Figure 2 to show weight loss rates. The peak rate of weight loss of raw kaolin occurred at about $500{ }^{\circ} \mathrm{C}$, and had almost finished releasing water from hydroxyl bonds by $800{ }^{\circ} \mathrm{C}$. However, for the modified kaolin, there were peaks below $300{ }^{\circ} \mathrm{C}$ which can be attributed to free water and bound water. The highest peaks presented much earlier than kaolin, below $300{ }^{\circ} \mathrm{C}$ for $\mathrm{HB}$ and $410{ }^{\circ} \mathrm{C}$ for HC. This implies that the hydrothermal treatment at higher pressures could push more water inside the mineral and produce a greater thermal stability. To further confirm the 
water or hydroxyl species in the sorbents, FTIR analysis was conducted (these curves are shown in Figure S1) between $3000-4000 \mathrm{~cm}^{-1}$ where the parallel vibration frequency of hydrogen-oxygen bond occurs. All sorbents possessed the board flat peaks at $3420 \mathrm{~cm}^{-1}$ that represents hydrogen bonds indicating adsorbed or bound water, while raw kaolin had four noticeable hydroxyl peaks (connected with aluminium atoms) between $3600-3700 \mathrm{~cm}^{-1}$ (Cheng et al., 2019). The rehydroxylation reported in some studies was not observed in this study, which may be attributed to the lower pressure of hydrothermal in this study than that in the literature (Zemenová et al., 2014; Kloužková et al., 2013).

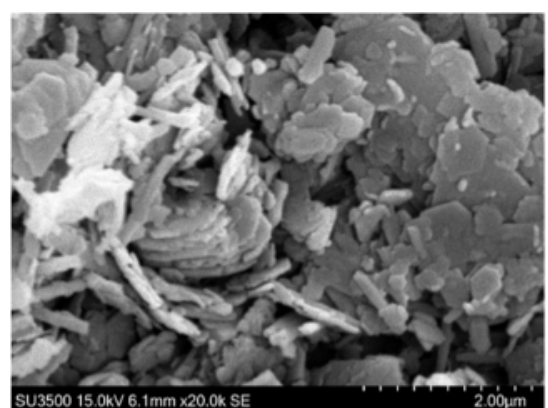

RK

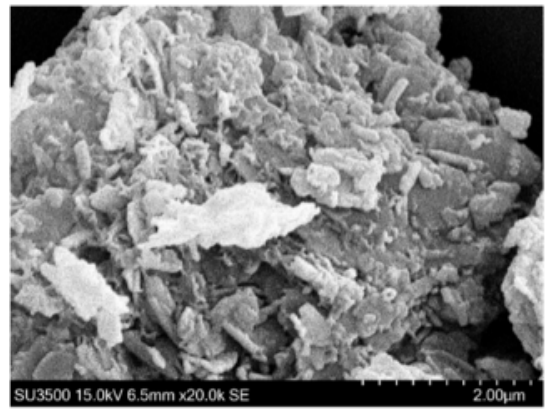

HA

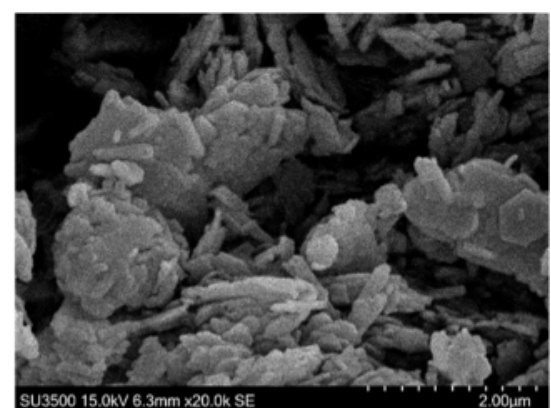

MK

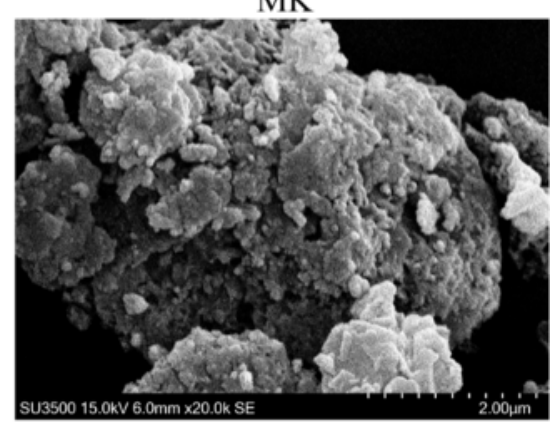

$\mathrm{HC}$

Figure 2. SEM images of sorbents RK, MK, HA and HC at a magnification of 20,000x.

SEM images of the sorbents are shown in Figure 2. The typical structure of layered pieces for raw kaolin was observed, while a molten structure was presented in the sample of metakaolin (MK) due to the calcination step. As for the modified sorbents, the morphologies were quite different from the former ones. The sample of HA retained its layered shape and sintered surface, as that of MK, but there were also small particles generated at a size of one hundred 
nanometres. Such particles were generated in a greater number in the sample of $\mathrm{HC}$ which had been produced with the higher pressure and had a very different morphology compared with RK and MK, where the structure seemed to have a great amount of disordered pore canals (see TEM images in Figure S2).

Table 1. BET analysis of sorbents

\begin{tabular}{cccc}
\hline & Surface Area & Average Pore & Pore Volume \\
Sample & $\left(\mathrm{m}^{2} / \mathrm{g}\right)$ & Size $(\mathrm{nm})$ & $\left(\mathrm{cm}^{3} / \mathrm{g}\right)$ \\
\hline MK & 18.2 & 49 & 0.22 \\
HA & 23.7 & 27 & 0.16 \\
HB & 51.8 & 18 & 0.24 \\
HC & 92.0 & 20 & 0.46 \\
RK & 19.3 & 35 & 0.17 \\
\hline
\end{tabular}

The BET analysis listed in Table. 1 further demonstrates the characteristic changes from RK to MK and MK to modified sorbents. Through calcination to generate MK, RK, water was released which created cavities so that the average pore size and pore volume were increased, while the surface area was not changed significantly due the effects of sintering and pore creation. With modification, HC gained four times more surface area, and the pore volume doubled relative to $\mathrm{MK}$, but shrank the average pore size. In fact, water played a role as mineraliser during the hydrothermal process, and reformed the layered structure of silicon and aluminium oxides (Sun et al., 2008). 


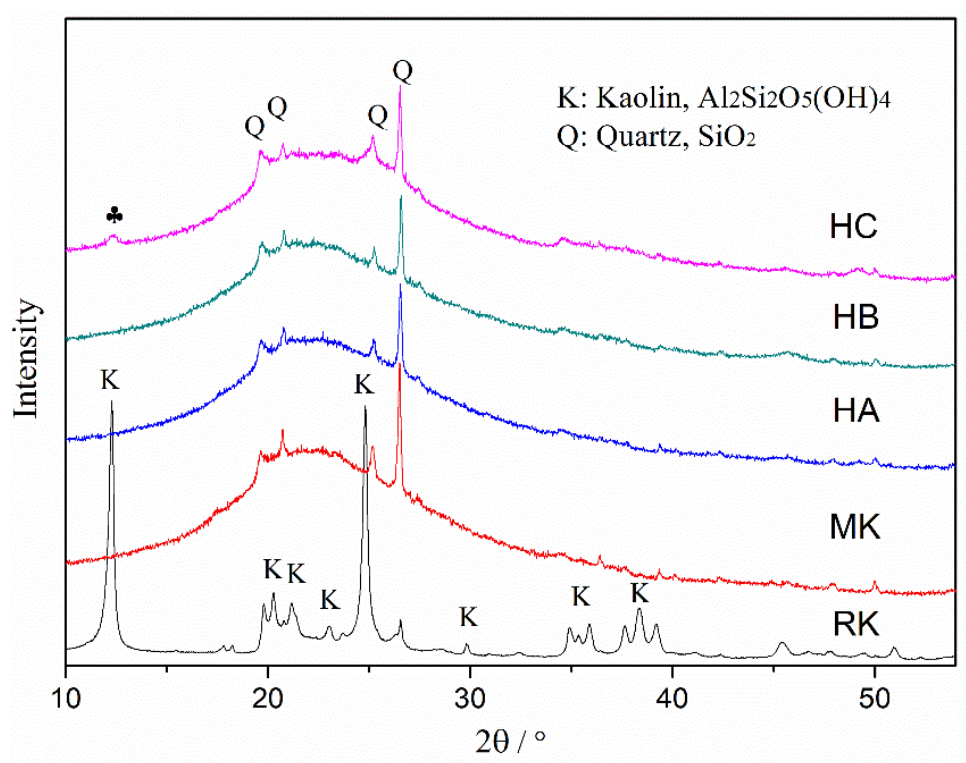

Figure 3. XRD analysis of sorbents

Figure 3 shows the XRD curves to analyse the different phases of sorbents. Quartz was the only crystalline phase detected in the samples of metakaolin and the modified sorbents because the kaolin phase disappeared after thermal treatment to obtain the metakaolin. The high flat and broad peak between $15-30^{\circ}$ indicated the amorphous phase of aluminosilicate (Cheng et al., 2019). Though all the curves of the modified sorbents and metakaolin were very similar, a weak peak (marked with a "club") occurred at $12.3^{\circ}$ for $\mathrm{HC}$ that was almost the characteristic peak of kaolin (calculated by the layer distance of the kaolin lattice cell). This phenomenon demonstrated that some local structures of kaolin have the tendency to be recovered at higher hydrothermal pressure. 

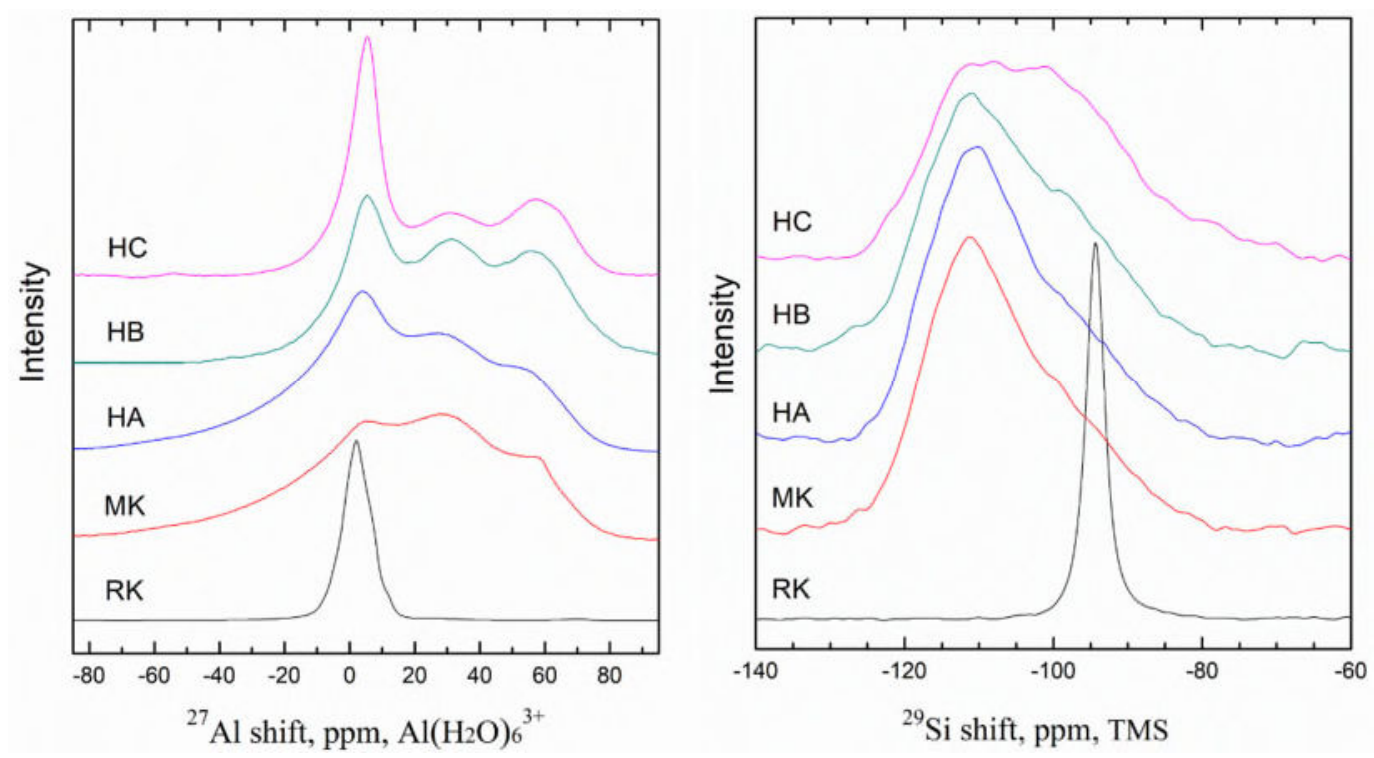

Figure 4. NMR analysis of $\mathrm{Al}$ and $\mathrm{Si}$ for sorbents. Abbreviation: TMS, trimethylsilane,

$$
\left(\mathrm{CH}_{3}\right)_{3} \mathrm{SiH}
$$

Although XRD could not recognise the difference between the amorphous structures, NMR analysis can shed some light on these smaller scale structures, these results are displayed in Figure 4. For aluminium, there are three kinds of peaks between 0-5 ppm, 28-32 ppm, and 57$62 \mathrm{ppm}$ which represent 6-coordinated, 5-coordinated and 4-coordinated aluminium (marked as $\mathrm{Al}^{\mathrm{VI}}, \mathrm{Al}^{\mathrm{V}}, \mathrm{Al}^{\mathrm{IV}}$ respectively). Raw kaolin only had $\mathrm{Al}^{\mathrm{VI}}$ for $\mathrm{AlO}_{6}$ octahedron, while $\mathrm{Al}^{\mathrm{V}}, \mathrm{Al}^{\mathrm{IV}}$ for metakaolin were observed owing to the dehydroxylation process (White et al., 2010). However, the pressured hydrothermal treatment seemed to recover some of the $\mathrm{AlO}_{6}$ octahedron, as the peak of $\mathrm{Al}^{\mathrm{VI}}$ was stronger with an increasing modification pressure but the proportions of $\mathrm{Al}^{\mathrm{V}}, \mathrm{Al}^{\mathrm{IV}}$ were decreased. This means through pressured hydrothermal treatment the unsaturated $\mathrm{Al}^{\mathrm{V}}, \mathrm{Al}^{\mathrm{IV}}$ reconnected with other atom groups such as hydroxyls and $\mathrm{SiO}_{4}$ tetrahedrons, which corresponded to the new peak in XRD analysis. More evidence was demonstrated in the silicon shifts in Figure 4. The sharp peak of RK at 93 ppm represents $\mathrm{Si}^{3}$ (connecting with three bridge oxygen atoms), and peaks of other minerals at $112 \mathrm{ppm}$ represent 
$\mathrm{Si}^{4}$ (connecting with four bridge oxygen atoms, which means all the four bonds of $\mathrm{SiO}_{4}$ group connects with another four $\mathrm{SiO}_{4}$ groups). The conversion from $\mathrm{Si}^{3}$ of $\mathrm{RK}$ to $\mathrm{Si}^{4}$ of $\mathrm{MK}$ was due to the dehydroxylation after calcination (Cheng et al., 2019). When comparing the curves between MK and modified sorbents, the pressured hydrothermal treatment seemed to increase the proportion of $\mathrm{Si}^{3}$ as the curves were lifted on the right side. The $\mathrm{SiO}_{4}$ groups connected with other atom groups and the tendency also corresponded with the aluminium shift analysis where we estimated that the aluminium might reconnect with $\mathrm{SiO}_{4}$ tetrahedrons.

3.2 The formation mechanism of the synthetic silicates

Under high pressures and high temperatures in aqueous solution, the solubility of silicon and aluminium such as hydrated silica $\mathrm{Si}(\mathrm{OH})_{4}$ and aluminium hydroxide $\mathrm{Al}(\mathrm{OH})_{3}$ were dramatically increased. Thus, the metakaolin was persistently solved to release silicate and aluminium which were dispersed in the water as precursors (Cassiers et al., 2002; Zhang et al., 2011). On the other hand, a part of solute agglomerated and precipitated into solid cores, so that sphere particulates in size of about $100 \mathrm{~nm}$ were seen in the SEM and TEM images. Also, the remained layered structure of metakaolin eventually disappeared. As the solubility of the silicate and aluminium determined the extent of chemical reformation and the formation of the fine particles, the tendency of elemental coordinate changes (NMR analysis in Figure 4) and the increasing of surface area (BET analysis in Table 1) from metakaolin MK to sorbent $\mathrm{HC}$ further demonstrated the effect of hydrothermal pressure.

\subsection{Characteristics of adsorption product}

To detect the changes after reaction, several characteristics including crystal phases, 
morphologies, surface areas and pore structures of adsorption product were analysed as follows. XRD analysis results of adsorption product are given in Figure S3, showing the crystal phases in the adsorption product at conditions of $700{ }^{\circ} \mathrm{C}$ and $900{ }^{\circ} \mathrm{C}$. At $700{ }^{\circ} \mathrm{C}$ only quartz peaks for all samples were seen, indicating the formation of amorphous phases for the rest of the bulk material. Mullite was generated at $900{ }^{\circ} \mathrm{C}$ and the peaks of mullite were sharper with the increasing modification pressure of the sorbents (See TGA curves in Figure 1), which might be attributed to the existence of moisture accelerating the mineralization (Temuujin et al. 1999). No peak representing lead content was detected in XRD curves, which could be due to the little mass of sorbate used in the test, while $\mathrm{PbSi}_{2} \mathrm{Al}_{2} \mathrm{O}_{8}$ has been reported as a product of reaction between kaolin and lead in some literature (Linak et al., 1993; Yu et al., 2020), following these reaction equations:

$$
\mathrm{PbCl} 2(\mathrm{~g})+\mathrm{Al} 2 \mathrm{O} 3 \cdot 2 \mathrm{SiO} 2 \cdot 4 \mathrm{H} 2 \mathrm{O}(\mathrm{kaolin}) \rightarrow \mathrm{PbO} \cdot \mathrm{A} 12 \mathrm{O} 3 \cdot 2 \mathrm{SiO} 2+2 \mathrm{H} 2 \mathrm{O}(\mathrm{g})+2 \mathrm{HCl}(\mathrm{g})
$$

$\mathrm{PbCl} 2(\mathrm{~g})+\mathrm{A} 12 \mathrm{O} 3 \cdot 2 \mathrm{SiO} 2($ metakaolin $)+\mathrm{H} 2 \mathrm{O}(\mathrm{g}) \rightarrow \mathrm{PbO} \cdot \mathrm{Al} 2 \mathrm{O} 3 \cdot 2 \mathrm{SiO} 2+2 \mathrm{HCl}(\mathrm{g})$ 


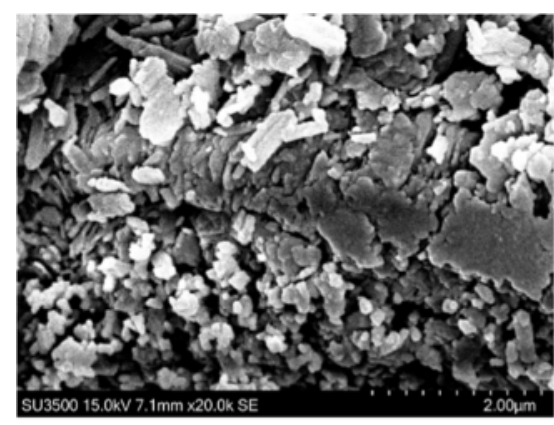

RK, $700^{\circ} \mathrm{C}$

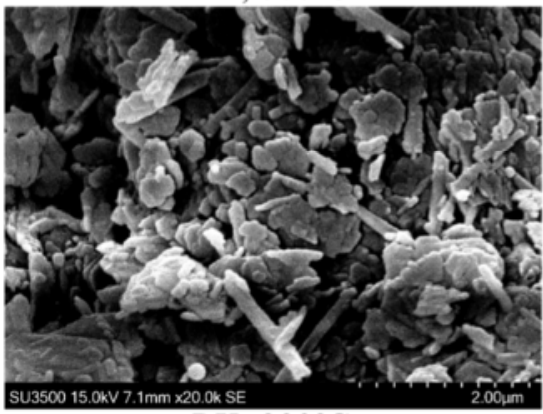

RK, $900^{\circ} \mathrm{C}$

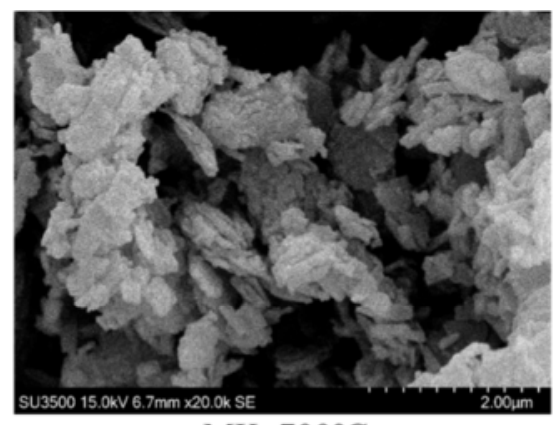

$\mathrm{MK}, 700^{\circ} \mathrm{C}$

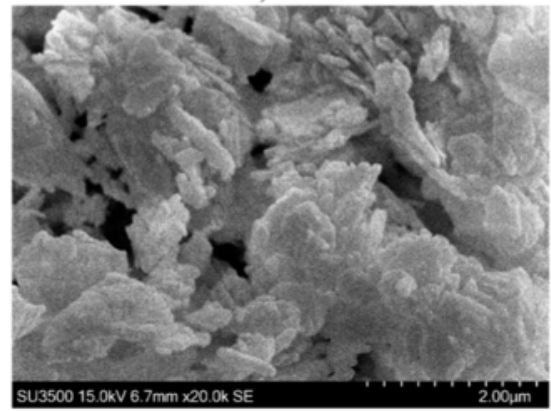

MK, $900^{\circ} \mathrm{C}$

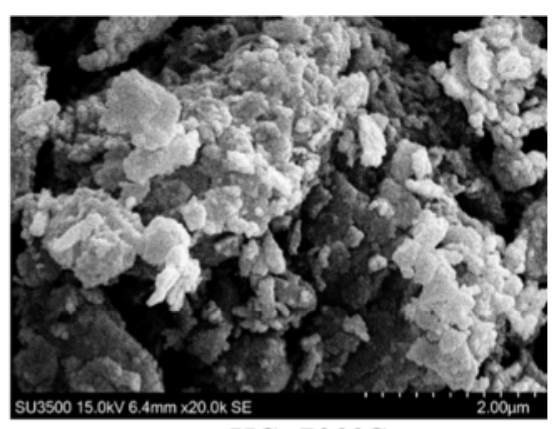

$\mathrm{HC}, 700^{\circ} \mathrm{C}$

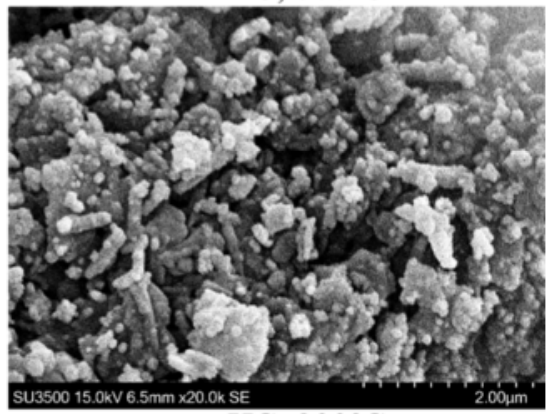

$\mathrm{HC}, 900^{\circ} \mathrm{C}$

Figure 5. SEM images of adsorption product in magnification of 20,000x.

Compared with XRD, the differences of morphologies (Figure 5) were quite clear for adsorption products between the sorbents. The sample of RK appeared to retain its layered structure, while for MK, the layered surface was heavily agglomerated and sintered because it was made from raw kaolin through calcination before use, which means it was heated for a much longer time. The product of HC presented little difference with before and after use, and its structure was maintained and kept at a much smaller size than that of its raw material (RK) or precursor (MK).

BET analysis of adsorption product at $900{ }^{\circ} \mathrm{C}$ (Table S3) matched the morphologies observed in the SEM images, as the products of modified sorbents and raw kaolin maintained their high surface areas while that of metakaolin almost completely lost its pore structure. Generally, the surface area and the average pore size for each sorbent decreased and increased, respectively. The reason for this could be the blockage of smaller pores through the sintering/melting effect that occurs at high temperatures. The modified sorbents showed a consistent tendency with 
modification pressure, where the adsorption product of $\mathrm{HC}$ had the largest surface area as well as pore volume, and the finest average pore size. When compared with the initial sorbents, it could be found that the pore volumes of $\mathrm{HB}$ and $\mathrm{HA}$ were increased while that of $\mathrm{HC}$ declined, which may have resulted from the explosion of moisture vaporization during heating and generating the extra pore volume, but that effect for $\mathrm{HC}$ was offset by pore collapse since its average pore size was too small to maintain all pore structure at high temperatures (Cassiers et al., 2002). However, their properties in BET analysis still surpassed those of RK after reaction. The extreme sample is MK, which lost most of its surface area and pore volume and the average pore size was expanded significantly because its pore framework was almost destroyed as it had been heated too long.

3.4 Adsorption efficiency, partitions of lead in the adsorption product

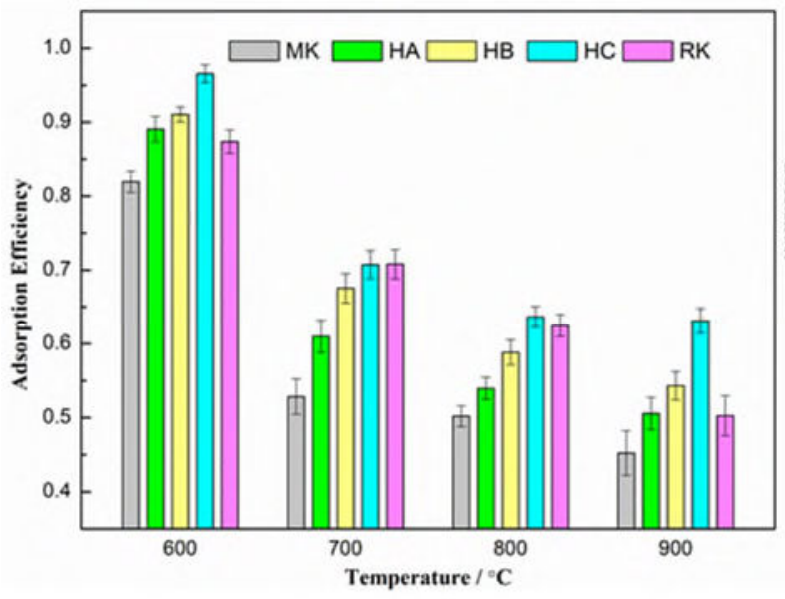

(a)

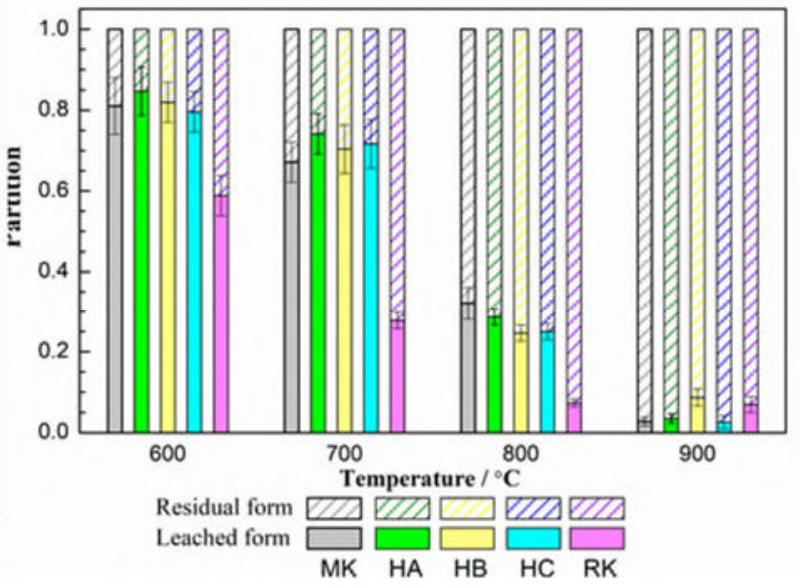

(b)

Figure 6. Adsorbed lead in the sorbents. (a)Total adsorption efficiency of lead. (b) Lead partitions in the adsorption product. Error bars were calculated from standard deviation $(n=3)$. Figure 6(a) displays the total adsorption efficiency of $\mathrm{PbCl}_{2}$ by sorbents, where the efficiency declined with operation temperature rising because the saturated vapour pressure of gaseous 
metal increased at a higher temperature so that it was harder to condense onto the sorbent surface.

Obviously, the ranking of sorbents efficiency for lead capture at each temperature tested was MK $<\mathrm{HA}<\mathrm{HB}<\mathrm{HC}$. When adding RK into the comparison, the sequence of sorbents based on efficiency of lead capture at $600{ }^{\circ} \mathrm{C}$ and $900{ }^{\circ} \mathrm{C}$ correlated with that of surface area (see Table 1 and Table S3). Although the effect of surface area was very clear, the performance of modified kaolin was better than that of raw kaolin, especially at high temperature $\left(900{ }^{\circ} \mathrm{C}\right)$ where the modified kaolin retained its pore structure. Though there is still a question about why the efficiencies of RK at $700{ }^{\circ} \mathrm{C}$ and $800{ }^{\circ} \mathrm{C}$ overtook HA and $\mathrm{HB}$, and were as high as $\mathrm{HC}$. To clarify into which species the adsorbed lead was captured by could reveal its adsorption behaviour, so a leaching test was conducted and these results are shown in Figure 6(b). The proportions of leached form lead for all sorbents decreased with increasing temperature, which means the diffusion of lead from the sorbent surface into the silicates lattice was accelerated by heating (Yu et al., 2020). Moreover, all partition values were below 0.1 at $900{ }^{\circ} \mathrm{C}$, where the apparent melting phenomenon occurred in SEM images for all samples, indicating that most of the lead in the sorbents at high temperature was stabilised and removed to a limited extent by leaching from the adsorption product (Zha et al., 2018).

Calculated as relative values, the partition rates of MK and modified sorbents were surprisingly almost equal between $600-800{ }^{\circ} \mathrm{C}$, while that of RK were much lower. Therefore, the diffusion effect of lead into the inner structures for RK was much stronger than other minerals. According to NMR analysis, these sorbents all possessed different proportions of $\mathrm{Si}$ and $\mathrm{Al}$ skeletons, and RK would also possess the similar NMR peaks of MK during heating process (Cassiers et al., 
2002). Thus, a variation in local aluminosilicate structures was not the main reason for that phenomenon of leaching characteristics.

On the other hand, the hydroxyls of raw kaolin were removed from the sorbent at a much higher temperature than that of the other sorbents which released water before the reaction began, according to TGA results. Consequently, the remaining hydroxyl may have induced sorbent melting to form liquid phase and enhanced lead diffusion from the surface into the silicate lattice. This is why the residual form for RK from the leaching experiments had a high proportion (more than $40 \%$ ) even at low temperature $\left(600{ }^{\circ} \mathrm{C}\right)$, and more adsorption sites on the surface were generated so that raw kaolin could be superior to the modified sorbents (HA and HB) with more surface area (at $700{ }^{\circ} \mathrm{C}$ and $800^{\circ} \mathrm{C}$ ), though its efficiency was still less than that of $\mathrm{HC}$.

\subsection{Discussion}

Through hydrothermal treatment of metakaolin, the modification sorbents gained a much larger surface area than raw kaolin and its chemical structure was reformed. The new structure was more stable at high temperature $\left(900{ }^{\circ} \mathrm{C}\right)$ so that it could maintain its mesoporous framework. The modified kaolin (HC) showed a greater adsorption efficiency than raw kaolin, although the proportions of lead leached from the spent modified sorbents at lower temperatures was higher than that of raw kaolin, which means these sorbents could have a higher tendency for leaching the captured lead. It was shown that this drawback could be overcome by rising the reaction temperature.

In the experimental methodology of this study, the sorbents had been heated for a relatively long time before reaction with the sorbate, which can be simulated as co-combustion in a grate 
furnace. But, it should be noted that its mechanism and performance could be different from that of direct injection into furnace where the reaction happens immediately and the sorbent only experiences flash calcination, so further work should be conducted in a reactor designed for a fast reaction such as a drop-tube furnace.

Though there have been several articles that reported metal capture by modified silicates, for the element lead, only one paper studied its adsorption by modified kaolin in a furnace (Lai et al., 2020). In that study, kaolin was modified by intercalation-exfoliation after calcination where chemicals potassium acetate, urea and dimethyl sulfoxide were used for three modification methods respectively, as well as ethanol for washing. Their tests were conducted using a sorbent to capture metals during coal combustion. At a combustion temperature of $900{ }^{\circ} \mathrm{C}$, the modified kaolin fixed $16 \%$ more lead than raw kaolin in the bottom ash, while in this work the new sorbent adsorbed $26 \%$ more lead than raw kaolin. This comparison demonstrated the adsorption ability of the material in this work is as effective as the intercalation-exfoliation modified kaolin.

It should be noted that the improved performance of this sorbent required higher modification pressures, which would increase a little higher production costs, though when compared with other modification methods of kaolin such as acid or base treatment and intercalation, this modification method uses only water and produces no effluent. As thermal energy is low-price energy which can be gained from exhaust heat or solar energy, this cheaper material produced via a green production route that is still able to achieve great performance at high-temperatures make this sorbent promising for in-furnace adsorption of heavy metals. 


\section{Conclusion}

In this study, pressurised hydrothermal treatment was used to produce a silicate based sorbent derived from kaolin for capturing gaseous $\mathrm{PbCl}_{2}$ in a fixed bed furnace, and the novel sorbent performed better than raw kaolin and metakaolin. An increasing modification pressure caused more surface area and pore volume of the material due to the higher concentration of silicates and aluminium hydroxide as precursors so that enhanced the adsorption reaction. The modified sorbents displayed amorphous phase where their chemical structures in atomic group scale were reformed. At higher temperature and even after long time heating, the sorbent still maintained most of its adsorption capacity and the fixed lead was very stable, which are critical for high-temperature sorbents. Moreover, though a little more thermal energy is required, which could be supplied from solar energy or waste heat, the green and cheap production of this material excels when compared to other modification processes of kaolin for this utility. In conclusion, the sorbent developed in this work has a high potential to be applied for in-situ removal of heavy metals at high temperature.

\section{Acknowledgement}

This project was supported by National Natural Science Foundation of China (No. 51676040), Natural Science Foundation of Jiangsu Province (BK20181281) and Postgraduate Research \& Practice Innovation Program of Jiangsu Province (KYCX18_0089).

\section{Reference}

Wang, X., Huang, Y., Niu, M., Wang, Y., Liu, C., 2016. Effect of multi-factors interaction on trace lead equilibrium during municipal solid waste incineration. J. Mater. Cycles Waste, 18, 287-295. 
Gale, T.K., Wendt, J., 2003. Mechanisms and models describing sodium and lead scavenging by a kaolinite aerosol at high temperatures. Aerosol. Sci. Technol., 37, 865-876.

Wang, X., Huang, Y., Zhong, Z., Yan, Y., Niu, M., Wang, Y., 2019. Control of inhalable particulate lead emission from incinerator using kaolin in two addition modes. Fuel Process. Technol., 119, 228-235.

Xu, Y., Liu, X., Wang, H., Zeng, X., Zhang, Y., Han, J.K., Xu, M., Pan, S., 2018. Influences of in-furnace kaolin addition on the formation and emission characteristics of PM2.5 in a $1000 \mathrm{MW}$ coal-fired power station. Environ. Sci. Technol., 52, 8718-8724.

Xing, H., Liu, H., Zhang, X., Deng, H., Hu, H., Yao, H., 2019. Enhanced sodium adsorption capacity of kaolinite using a combined method of thermal pre-activation and intercalation-exfoliation: Alleviating the problems of slagging and fouling during the combustion of Zhundong coal. Fuel, 239, 312-319.

Wang, G., Jensen, P.A., Wu, H., Frandsen, F.J., Sander, B., Glarborg, P., 2018. Potassium Capture by Kaolin, Part 2: K2CO3, KCI, and K2SO4. Energy Fuels, 32, 3566-3578.

Pťcek, P., Opravil, T., Soukal, F., Wasserbauer, J., Másilko, J., Barácek, J., 2013. The influence of structure order on the kinetics of dehydroxylation of kaolinite. J. Eur. Ceram. Soc., 33, 2793-2799.

Gasparini, E., Tarantino, S.C., Ghigna, P.L., Riccardi, M.P., Cedillo-González, E.I., Siligardi, C., Zema, M,. 2013. Thermal dehydroxylation of kaolinite under isothermal conditions. Appl. Clay Sci., 80, 417-425.

Zhang, Z., Liu, J., Yang, Y., Shen, F., Zhang, Z., 2018. Theoretical investigation of sodium capture mechanism on kaolinite surfaces. Fuel, 234, 318-325.

Wang, X., Huang, Y., Pan, Z., Wang, Y., Liu, C., 2015. Theoretical investigation of lead vapor adsorption on kaolinite surfaces with DFT calculations. J. Hazard. Mater., 295, 43-54. 
Zhang, X., Liu, H., Xing, H., Wang, G., Deng, H., Hu, H., Li, X., Yao, H., 2019. Correlations between the sodium adsorption capacity and the thermal behavior of modified kaolinite during the combustion of Zhundong coal. Fuel, 237, 170-177.

White, C.E., Provis, J.L., Proffen, T., Riley, D.P., Van Deventer, J.S.J., 2010. Density functional modeling of the local structure of kaolinite subjected to thermal dehydroxylation. J. Phys. Chem. A, 114, 4988-4996.

Yu, M., Huang, Y., Xia, W., Zhu, Z., Fan, C., Liu, C., Dong, L., Xu, L., Liu, L., Zha, J., Wang, X., 2020. PbCl2 Capture by Kaolin and Metakaolin under Different Influencing Factors of Thermal Treatment. Energy Fuels, 34, 2284-2292.

Temuujin, J., Okada, K., MacKenzie K., Jadambaa, T., 1999. The effect of water vapour atmospheres on the thermal transformation of kaolinite investigated by XRD, FTIR and solid state MAS NMR. J. Eur. Ceram. Soc., $19,105-12$.

Linak, W.P., Wendt, J.O.L., 1993. Toxic metal emissions from incineration-Mechanisms and control. Prog. Energy Combust. Sci., 19, 145-185.

Wang, X., Chen, M., Liu, C., Bu, C., Zhang. J., Zhao, C., Huang, Y., 2018. Typical gaseous semi-volatile metals adsorption by meta-kaolinite: A DFT study. Int. J. Environ. Res. Public Health, 15, 1-14.

Zhang, Y., Liu, X., Xu, Y., Sun, W., Xu, M., 2017. Investigation of reducing ultrafine particulate matter formation by adding modified montmorillonite during coal combustion. Fuel Process. Technol., 158, 264-271.

Sun, W., Liu, X., Xu, Y., Zhang, Y., Chen, D., Chen, Z., Xu, M., 2018. Effects of the modified kaolin sorbents on the reduction of ultrafine particulate matter (PM0.2) emissions during pulverized coal combustion. Fuel, 215, $153-160$.

Hartanto, D., Kurniawati, R., Pambudi, A.B., Utomo, W.P., Leaw, W.L., Nur, H., 2019. One-pot non-template synthesis of hierarchical ZSM-5 from kaolin source. Solid State Sci., 87, 150-154. 
Xu, Y., Liu, X., Wang H., Zhang, Y., Qi, J., Xu, M., 2019. Investigation of simultaneously reducing the emission of ultrafine particulate matter and heavy metals by adding modified attapulgite during coal combustion. Energy Fuels, 33, 1518-1526.

Zhang, X., Liu, H., Xing, H., Li, H., Hu, H., Li, A., 2017. Improved sodium adsorption by modified kaolinite at high temperature using intercalation-exfoliation method. Fuel, 191, 198-203.

Lai, X., Zhong Z., Xue, Z., Huang Y., 2019. Experimental study on enrichment of heavy metals by intercalationexfoliation modified kaolin during coal combustion. Environ. Technol., 25, 1479-1487.

Zhang, X., Liu H., Xing, H., Wang G., Li, H., Xiao, K., Liu, W., Yu, Y., Yao, H., 2019. Investigation of potassium vapor time-resolved adsorption and potassium-sodium competitive adsorption by modified kaolinite. Fuel, 258.

Krol, M., Rozek, P., 2018. The effect of calcination temperature on metakaolin structure for the synthesis of zeolites. Clay Minerals, 53, 657-663.

Wu, S., Lin, H., 2013. Synthesis of mesoporous silica nanoparticles. Chem. Soc. Rev., 42, 3862-3875.

Zhang, R., Hu, S., Zhang, X., 2011. Dissolution rates of silicate minerals in water from a subcritical to a supercritical state: Effect of solvent properties. Res Chem Intermed, 37, 243-258.

Hayashi, H., Hakuta, Y., 2010. Hydrothermal Synthesis of metal oxide nanoparticles in supercritical water. Materials, 3, 3794-3817.

Sun, Y., Wang, Y., Lu, Y., Wang, T., Luo, G., 2008. Subcritical water treatment: A simple method to prepare porous glass with a core-shell structure. J. Am. Ceram. Soc., 91,103-109.

Zemenová, P., Kloužková, A., Kohoutková, M., Král, R.M., 2014. Investigation of the first and second dehydroxylation of kaolinite. J. Therm. Anal. Calorim., 116, 633-639.

Kloužková, A., Zemenová, P., Kohoutková, M., Kloužek, J., 2013. Hydrothermal rehydroxylation of kaolinite studied by thermal analysis. Ceram - Silikaty,57, 342-7. 
Zha, J., Huang, Y., Xia, W., Xia, Z., Liu, C., Dong, L., Liu, L., 2018. Effect of mineral reaction between calcium and aluminosilicate on heavy metal behavior during sludge incineration. Fuel, 229, 241-247.

Cheng, Y., Xing, J., Bu C., Zhang J., Piao, G., Huang, Y., Xie, H., Wang, X., 2019. Dehydroxylation and structural distortion of kaolinite as a high-temperature sorbent in the furnace. Minerals, 9.

Cassiers, K., Linssen, T., Mathieu, M., Benjelloun, M., Schrijnemakers, K., Van Der Voort P., Vansant, E. F., 2002. A detailed study of thermal, hydrothermal, and mechanical stabilities of a wide range of surfactant assembled mesoporous silicas. Chem. Mater., 14, 2317-2324. 